\title{
Case Report: Candida Ball in the Esophagus
}

\author{
Mohammad Al-Shoha MD ${ }^{1 *}$, Nayana George $\mathrm{MD}^{1}$ and Benjamin Tharian MD ${ }^{1,2}$ \\ ${ }^{1}$ Department of Internal Medicine, University of Arkansas for Medical Sciences, USA \\ ${ }^{2}$ Department of Medicine, Division of Gastroenterology and Hepatology, USA
}

Submission: February 10, 2017; Published: June 16, 2017

"Corresponding author: Mohammad Al-Shoha, Department of Internal Medicine, University of Arkansas for Medical Sciences, Internal Medicine, 4301 W. Markham Street, Slo t\#634, Little Rock, AR 72205, USA, Tel: 5015905554, Email: moalshoha@uams.edu

\begin{abstract}
Candida albicans is the most common well known cause of infectious esophagitis. Although most patients with Candida esophagitis are immunocompromised, about $25 \%$ have scleroderma, achalasia, or other causes of esophageal dysmotility that would allow the fungi to overgrow and colonize the esophagus, with subsequent esophagitis [1,2]. Esophageal candidiasis usually manifests as white mucosal plaque-like lesions but it has been reported in the literature that it can manifest as an esophageal mass. We are reporting a case of recurrent esophageal candidiasis manifesting on the Esophagogastroduodenoscopy (EGD) as an obstructing mass.
\end{abstract}

\section{Case report}

A 70-year old African American male patient who presented with complaints of gradually worsening dysphagia for both solids and liquids with an EGD revealing a nearly obstructing mass in the esophagus $25 \mathrm{~cm}$ from incisors occupying $75-99 \%$ of the circumference of the esophagus with the inability to traverse the obstructing mass using the $11 \mathrm{~mm}$ diameter scope. Biopsies were taken from the mass showing acute inflammatory exudates and necrotic debris consistent with erosive esophagitis with rare Candida organisms identified. Patient was prescribed a course of PPI and antifungal agent and his dysphagia has improved.

Three years later, he presented to our hospital with recurrent dysphagia, odynophagia and significant weight loss. He was ill-appearing and cachectic but his physical examination was otherwise unremarkable. The initial laboratory work-up showed normal complete blood count, acute renal injury with creatinine $11.5 \mathrm{mg} / \mathrm{dL}$, sodium 127 , potassium 3.9 , normal TSH and negative HIV testing. Repeat EGD revealed a mass at $25 \mathrm{~cm}$ from incisors (image $\mathrm{A}, \mathrm{B}$ ) with a biopsy revealing active esophagitis with intraepithelial fungi consistent with Candida with no dysplasia and malignancy. The patient was treated with oral fluconazole for two weeks with partial improvement in the patient's symptoms.

Repeat EGD was arranged for follow up to make sure that the mass has resolved and to look for any hidden malignancy, it was done 3 months later showing a pinhole stricture with scarring at $25 \mathrm{~cm}$ from the incisors (image $\mathrm{C}$ ), biopsies from the stricture were taken showing esophageal mucosa with reactive changes but no malignancy. EUS was also performed and did not show any masses (Figure 1a, 1b \& 1c).

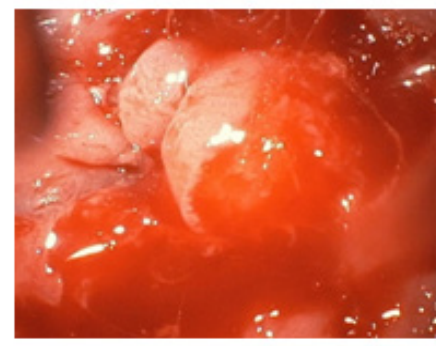

A

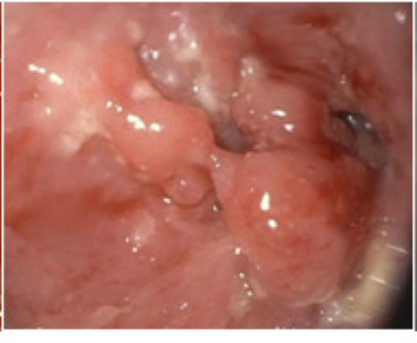

B

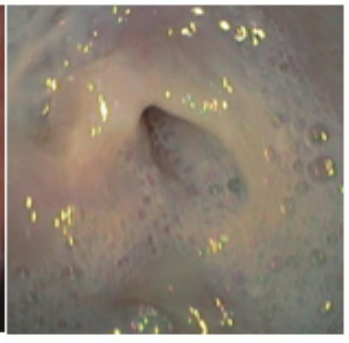

C

Figure 1 


\section{Discussion}

Candidal infections in the gastrointestinal tract can rarely cause complications. These complications include fungal balls or masses, perforation of the oesophagus [3], stomach [4] and intestine [5] and formation of trachea-oesophageal fistula [6]. Fungal masses have been also reported in the myocardium [7], pleural cavity [8], in a peritoneal dialysis catheter [9], paranasal air sinuses and are well recognized in the urinary tract [1013]. Hepatobiliary complications of candidal infection include hepatosplenic granulomata [14] and acalculus cholecystitis [15]. Biliary tract obstruction secondary to a fungal mass in the biliary tree in association with biliary stasis [16-18] has been reported. The diagnosis of Candida esophagitis manifesting as an esophageal mass has been quite challenging in terms of confirming the diagnosis and ruling out any evidence of malignancy.

Rajablou et al. [19] reported a case of a CLL patient who presented with fever, nausea, vomiting, and upper abdominal pain with the EGD revealing a circumferential ulcerated mass in the distal esophagus with the biopsy showing ulcerated mucosa, with abundant granulation tissue, numerous yeast, and pseudohyphal fungal forms consistent with Candida albicans, duodenum with no evidence of malignancy. Patient was successfully treated with a course of fluconazole and follow up EGD showed healing of the previous lesions.

Mehmet et al. [1] reported a case of a 71-year-old man with history of achalasia status post esophageal balloon dilatation and Botox therapy presented to the hospital with anorexia, difficulty in swallowing and epigastricpain.EGD revealed mid-esophageal diverticula, diffuse edematous mucosa, mucosal granularity, and a $5 \times 10 \mathrm{~mm}$ focal mucosal protuberance with non-smooth contours superior to the $\mathrm{Z}$ line, with suspicion of malignancy. Endoscopic biopsy specimen yielded fungal esophagitis. Culture of the biopsy material yielded Candida albicans as the etiologic microorganism and the patient was successfully treated with antifungal therapy with improvement of the patient's symptoms.

Hyun JJ et al. [20] described a case of a 31-year-old immunocompetent woman with history of previously treated candida esophagitis seven years ago who presented with five years of recurrent worsening dysphagia. The endoscopy revealed esophageal luminal narrowing at $23 \mathrm{~cm}$ from the central incisor, with irregular mucosa and multiple ulcers and whitish exudates. Multiple biopsies revealed candidal infection which improved transiently after a course of fluconazole but then worsened again with the EGD revealing worsening stenosis.

Horan et al. [21] reported a case of a 52-year-old woman presented with progressive dysphagia over 6 months with weight loss with multiple EGDs all revealing oesophageal candidiasis and a papillomatous growth in the midoesophagus. Histology showed severely dysplastic squamous epithelium with no definitive stromal invasion. Endoscopic ultrasound (EUS) showed a circumferential growth in the upper to mid-oesophagus, involving all the oesophageal layers to the adventitia with clear breach of the adventitia. A positron emission tomography-computed tomography (PET-CT) scan demonstrated a metabolically active large concentric thickening of the oesophagus from the level of the carina to the inferior pulmonary vein, with increased fluorodeoxyglucose (FDG) activity. She underwent a three-stage oesophagectomy. Macroscopic and microscopic examination of the oesophagogastrectomy specimen revealed a well-differentiated squamous cell carcinoma (SCC) arising on the background of surface squamous papillomatosis. The final diagnosis was carcinoma cuniculatum, a rare morphological variant of squamous cell carcinoma

A prospective study on the frequency of gastro-esophageal candidiasis in 465 patients who underwent endoscopy, showed that candidiasis was more prevalent in patients with esophageal carcinoma $(27 \%)$ than in patients with other forms of mucosal injury, such as esophagitis (15\%) [22,23]. Although candidiasis can develop secondary to malignancy, possibly due to impaired antifungal host defense due to mucosal damage, there is increasing evidence that Candida infection itself has carcinogenic properties. One important mechanism that has been proposed to underlie this phenomenon is the catalytic activity of Candida, which facilitates the production of carcinogenic nitrosamines such as nitroso-N-methylbenzylamine (NBMA) from their precursors [22,24].

Our case demonstrates a patient with esophageal candidiasis that is manifesting as an obstructing esophageal mass with the biopsy revealing active esophagitis with intraepithelial fungi consistent with Candida with no dysplasia and malignancy. EUS was performed due to concerns of underlying malignancy and it showed a short stricture with scarring which could have resulted from the healing process of the mass but no evidence of malignancy.

\section{References}

1. Mehmet R, Cem A, Muammer A, Halil IB (2011) Candida esophagitis mimicking esophageal carcinoma. Turk J Gastroenterol 22(6): 648657.

2. Levine MS, Macones AJ, Laufer I (1995) Candida esophagitis: accuracy of radiographic diagnosis. Radiology 154(3): 581-587.

3. Gaissart HA, Breuer CK, Weissberg A, Mermel L (1999) Surgical management of necrotising candida esophagitis. Ann Thoracic Surg 67(1): 231-233.

4. Faure-Fontela MA, Bracho-Blanchet E, Yanez Molina C, Barragan-Tame L (1997) Gastric perforation with candida tropicalis invasion in a previously healthy girl. Mycoses 40(5-6): 175-177.

5. Adderson EE, Pappin A, Pavia AT (1198) Spontaneous intestinal perforation in premature infants: a distinct clinical entity associated with systemic candidiasis. J Paed Surg 33(10): 1463-1467.

6. Serrano N, Cortes JL (1996) An unusual presentation of tracheooesophageal fistula. Int Care Med 22: 717-718.

7. Alam M, Higgins R, Alam Z, Jankiraman N, Gorman M (1998) Aspergillus fungal mass detected by transesophageal echo. J Am Soc Echocardiogr 11(1): 83-85. 
8. Kurup PV, Sharma VN, Viswanathan R, Sandhu RS, Randhawa HS, et al. (1968) Pulmonary fungal ball due to Nocardia species. Scand J Resp Dis 49: 9-14.

9. Gadallah MF, White R, Shahawy MA, Abreo F, Oberle A, et al. (1995) Fungal ball in a peritoneal dialysis catheter. Am J Nephrol 15(4): 348352.

10. Stevens MH (1978) Aspergillus of the frontal sinus. Arch Otolaryngol 104(3): 153-156.

11. Camiter CV, Donald M, Minton J, Yalla SV (1996) Fungal bezoar and bladder rupture secondary to candida tropicalis. Urology 47(3): 439441

12. Keung Y K, Khan A, Skinner E, Douer D (1993) Localised renal pelvic fungal ball in a patient undergoing bone marrow transplantation. Acta Haematol 89: 160-162.

13. Dembner AG, Dfister RC (1977) Fungal infection of the urinary tract: demonstration by antegrade pyelography and drainage by percutaneous nephrostomy. Am J Roentgenol 129: 415-418.

14. Kelekis NL, Semelka RC, Jeon HJ, Salleh AS, Shea T C, et al. (1996) Dark ring sign finding in patients with fungal liver lesions and transfusionalhaemosiderosis undergoing treatment with antifungal antibiotics. Magn Reson Imaging 14(6): 615-618.

15. Peison B, Benison B (1996) Aciteacalculus cholecystitis secondary to Candida albicans. N J Med 93(4): 39-42.
16. Uplacher R, Wholey MH, Amaral NM, Lima S (1982) Parasitic and mycotic causes of biliary obstruction. Gastrointest Radiol 7(1): 173179.

17. Gupta N M, Chaudhury A, Talwar P (1985) Candidal obstruction of the bile duct. Br J Surg 72: 13.

18. Ho F, Snape WJ, Venegas R, Lechago J, Klein S (1988) Choledochal fungal ball an unusual cause of biliary obstruction. Dig Dis Sci 33(8): 1030-1034.

19. Maryam R, Ganz RA, Kenneth P (2010) Candida infection presenting as multiple ulcerated masses. Gastrointestinal Endoscopy 65(1): 2007.

20. Hyun JJ, Chun HJ, Keum B (2010) Candida esophagitis complicated by esophageal stricture. Endoscopy 42: E180-E181

21. Maebh H, Andrea W, Orla Mc C, Cian M, Narayanasamy R, John V (2014) Severe Dysphagia, Candidiasis, and an Oesophageal Mass, but Over 50 Biopsies Negative for Malignancy. Dysphagia 29(1): 109-112.

22. Delsing CE, Bleeker-Rovers CP, van de Veerdonk FL, Tol J, van der Meer JW, et al. (2011) Association of esophageal candidiasis and squamous cell carcinoma. Medical Mycology Case Reports 1(1): 5-8.

23. Scott BB, Jenkins D (1982) Gastro-oesophageal candidiasis. Gut 23(2): 137-139.

24. Krogh P (1990) The role of yeasts in oral cancer by means of endogenous nitrosation. Acta Odontologica Scandinavica 48(1): 85-88.

This work is licensed under Creative

Commons Attribution 4.0 License

DOI: $10.19080 /$ ARGH.2017.06.555677
Your next submission with JuniperPublishers will reach you the below assets

- Quality Editorial service

- Swift Peer Review

- Reprints availability

- E-prints Service

- Manuscript Podcast for convenient understanding

- Global attainment for your research

- Manuscript accessibility in different formats

( Pdf, E-pub, Full Text, audio)

- Unceasing customer service

Track the below URL for one-step submission https://juniperpublishers.com/online-submission.php 